\title{
Measuring Happiness to Guide Public Policy Making: A Survey of Instruments and Policy Initiatives
}

\author{
Laura Musikanski \\ Happiness Alliance
}

\begin{abstract}
This author examines subjective indicators of well-being as they relate to the happiness movement, a global effort to create a new economic paradigm. The essay focuses on the prominent international institutions that are developing happiness metrics as well as agencies exploring the use of happiness data for crafting supportive public policy. A definition of happiness metrics, based on international institutions, identifies the primary questions that compose perceived happiness and how this data can be used.
\end{abstract}

Keywords: happiness, subjective well-being indicators, new economic paradigm, beyond GDP, public policy

\section{Introduction}

The Occupy Wall Street demonstrations and similar events surfaced widespread anger with economic and social inequality. It was a movement that gripped the news media's attention and raised the economic consciousness of huge numbers of people who began to understand the vast disparity between the haves and the have-nots in developed economies. The happiness movement followed close on the Occupy movement's heels, with an official launch on April 4 of 2012 at the end of the United Nations' High Level Meeting on Well-Being and Happiness: Defining a New Economic Paradigm held at the United Nations headquarters in New York City.

The happiness movement provides pathways to an economy and society focused on the well-being of all. The development and use of happiness metrics to guide public policy is one such pathway.

Happiness metrics, for the purposes of this essay, are indicators of subjective well-being that include at least one measure for a person's satisfaction with life, affect, or eudaimonia.

\section{Toward A New Economic Paradigm}

The government's dominant measure to guide public policy is gross domestic product (GDP). GDP is the market value of all goods and services produced within a country in a year. The Stiglitz, Sen, and Fitoussi (2009) report to the United Nations shed doubt on the usefulness of GDP and called for "our measurement system to shift emphasis from measuring economic production to measuring people's well-being" (italics theirs, p. 12). Their report set off a cascade of activity, including the implementation of "beyond GDP" measurements in the European Union (http://www.brainpoolproject.eu/) that set forth recommendations for the use of alternatives to GDP measurements to guide policy (Whitby, Seaford, Berry, \& BRAINPOoL Consortium Partners, 2014). The 2015 World Happiness Report (Helliwell, Layard, \& Sachs, 2015) provides examples of how to 
use happiness for public policy and summarizes the state of the movement: "Happiness is increasingly considered a proper measure of social progress and a goal of public policy" (p. 3).

In the United States, a panel drawn from the National Academy of Sciences, National Academy of Engineering, and Institute of Medicine issued a report, Subjective Well-Being: Measuring Happiness, Suffering, and Other Dimensions of Experience (National Research Council, 2013), in an effort to provide guidance about the use of subjective well-being measurements to "inform social and economic policies" (p. 2).

If pursuit of wealth and accumulation of property leads to happiness and well-being for all, then there is no need for happiness metrics. However, Kasser's (2002) findings identified that "a strong relative focus on materialistic values is associated with low well-being" (p. 21), supporting an earlier finding by Kasser and Ryan (1993) that when pursuit of wealth is synonymous with pursuit of happiness, a culture emerges in which financial success, image, and status are highly valued, and family, personal happiness, and caring for others and the environment is diminished. Pickett and Wilkinson (2009) demonstrated the deleterious impact on population segments, as well as society overall when GDP is the main measure guiding public policy. Kasser's research indicates that measurements have a direct influence on cultural values, which drive behavior. So, to change behaviors, sometimes it is necessary to change what is measured (Happiness Alliance, 2014).

\section{Subjective Versus Objective}

The shift from a singular focus on GDP to a more comprehensive set of measurements is best served if both objective and subjective metrics are used (Stiglitz et al., 2009, p. 15). Zencey (2013) points out combining objective and subjective measurements "to get 'beyond GDP' . . . is likely to be more successful more quickly than either measurement alone" (p. 4).

\section{Subjective and Objective Measures}

Objective measurements encompass the observable, something that can be easily measured like income, energy use, and high-school dropout rates. Subjective measurements capture the unobservable. Data is collected by asking questions about one's judgments, preferences, perceptions, needs, and time use.

Subjective indicators can measure subjective or objective concepts (Organisation for Economic Cooperation and Development [OECD], 2013b, p. 47). For example, questions about affect measure subjective concepts (i.e. "Overall, how happy or anxious did you feel yesterday?"), but a question asking whether one thinks there is less crime in a neighborhood or region measures an objective concept, which can be verified (i.e. crime reports). One use for subjective data of objective concepts is to determine the best allocation of resources to support an increase in policing or to fund a community event for a neighborhood when the perceived crime rate is high but actual crime rate is low. Objective data can address that misconception, but the persistence of the perception, perhaps from excessive emphasis on crime in the media, does influence one's overall sense of well-being.

\section{Categories of Subjective Indicators}

Happiness is measured using subjective well-being measurements (OECD, 2013b, p. 12). According to Stiglitz and colleagues (2009), there are two categories of subjective indicators: those that capture life evaluations and people's thoughts about the circumstances of their lives and those that capture positive and negative affect (people's emotions; p. 43). The OECD Guidelines on Measuring Subjective Well-Being (OECD, 2013b) adds eudaimonia, defining it as going 
beyond the respondent's reflective evaluation and emotional state to focus on

functioning and the realization of the person's potential .... comprising

autonomy, competence, interest in learning, goal orientation, sense of

purpose, resilience, social engagement, caring and altruism. (p.34)

Eurostat (2015) also identifies the three ways of measuring subjective well-being as "three distinct but complementary sub-dimensions: life satisfaction, based on an overall cognitive assessment; affects, or the presence of positive feelings and absence of negative feelings; and eudaimonics, the feeling that one's life has a meaning" (p. 2). These three subjective measurements, life evaluations (which include circumstances), affect, and eudaimonia, compose "happiness measurements."

According to the OECD Guidelines on Measuring Subjective Well-Being (OECD, 2013b), the three most prominent instruments are the Cantril Ladder of Life Scale, the World Values Survey overall life satisfaction question, and that used by the United Kingdom Office of National Statistics. Sample questions are as follows:

- Cantril Ladder: Please imagine a ladder with steps numbered from 0 at the bottom to 10 at the top. Suppose we say that the top of the ladder represents the best possible life for you and the bottom of the ladder represents the worst possible. If the top step is 10 and the bottom step is 0 , on which step of the ladder do you feel you personally stand at the present time?

- World Values Survey: All things considered, how satisfied are you with life as a whole nowadays?

- United Kingdom: Overall, how satisfied are you with your life nowadays? (OECD, 2013b, Annex A)

Affect questions range from those developed Diener, Wirtz, et al. (2009), Michael Fordyce (1988), and the United Kingdom's Office of National Statistics (2015). The questions are as follows:

- Diener, Wirtz, et al. (2009): Please think about what you have been doing and experiencing during the past 4 weeks. Then report how much you experienced each of the following feelings: positive, negative, good, bad, pleasant, unpleasant, happy, sad, afraid, joyful, angry, contented.

- Fordyce (1988): Consider your emotions a moment further. On the average, what percent of the time do you feel happy? What percent of the time do you feel unhappy? What percent of the time do you feel neutral (neither happy nor unhappy)?

- United Kingdom Office of National Statistics (2015): Overall, how happy did you feel yesterday? Overall, how anxious did you feel yesterday?

Eudaimonia can be measured using the Diener and Biswas-Diener (2008) Psychological Well-Being Scale, Huppert and So's (2013) Flourishing Index, or the United Kingdom Office of National Statistics (2015) questions. The questions are as follows:

- Diener and Biswas-Diener (2008): Below are eight statements with which you may agree or disagree ... indicate your agreement with each item by choosing a response for each statement. "I lead a purposeful and meaningful life." "My social relationships are supportive and rewarding." "I am engaged and interested in my daily activities." "I actively contribute to the happiness and well-being of others." "I am competent and capable in the activities that are important to me." "I am a good person and live a good life." "I am optimistic about my future." "People respect me." 
- Huppert and So (2013): To what extent do you agree with the following statements? "I lead a purposeful and meaningful life." "I am engaged and interested in my daily activities." "I am optimistic about my future." "Most days I feel a sense of accomplishment from what I do." "In general, I feel very positive about myself."

- United Kingdom Office of National Statistics (2015): Overall, to what extent do you feel the things you do in your life are worthwhile?

\section{Can Happiness Be Measured?}

A common charge against the use of subjective well-being metrics by policy makers and others is that happiness cannot be measured. Helliwell, in a keynote speech at the Measuring Subjective WellBeing for Policy and Individual Use conference held on Mexico on April 17, 2014 (INEGInforma, 2014), stated,

the reason in part, there is such tension is that Amartya Sen has not yet been convinced that the kind of data we collect in happiness research represents what he thinks ought to be collected and used as a core measure ... we are close to coming to the end of that discussion because there is now enough data of various kinds available we can now put some empirical structure on what was previously a philosophical debate. (5:38-6:08)

Moreover, the issuance of the 2012, 2013, and 2015 World Happiness Reports by Columbia University and the Sustainable Development Solutions Network, as well as the issuance of the OECD Guidelines on Measuring Subjective Well-Being (OECD, 2013b), render this question moot. The real question today is how to use subjective well-being measurements, including happiness measurements.

\section{Uses for Subjective Well-Being Measurements}

Stiglitz and colleagues (2009) identified eight areas where well-being metrics could be useful for policy makers:

i. Material living standards (income, consumption, and wealth),

ii. Health,

iii. Education,

iv. Personal activities including work,

v. Political voice and governance,

vi. Social connections and relationships,

vii. Environment (present and future conditions),

viii. Insecurity of an economic as well as a physical nature (2009, pp. 13-14).

The same year, Diener, Lucas, Schimmack, and Helliwell (2009) identified uses of subjective indicators to include understanding what motivates behavior, thereby allowing policy makers to "use information about these reactions and the factors that affect them to help guide societies towards desirable futures" (p. 47). In an "experimenting society" (italics theirs), they point out, subjective wellbeing indicators "help judge outcomes ... (where) ... Policy makers often engage in protracted debates about how to solve specific problems and how to enhance quality of life ... debates often continue for decades ... and little evidence is available to evaluate their effects" (p. 61). They point out that subjective well-being metrics can be used for decisions where resources are scarce or the problems are severe, there are trade-offs impacting various domains and no common metric, or the “apples verses oranges” problem (pp. 54-55). 
Subjective well-being measurements lend themselves to granularity, allowing one to "pinpoint the groups in which misery needs to be addressed and the conditions that led to this distress" (Diener, Lucas, et al., 2009, p. 59). In this way, subjective well-being indicators can be used to define and refine highly political or otherwise charged and complex concepts such as poverty, social justice, and disability (p. 62).

In the 2013 World Happiness Report, O'Donnell writes, "Governments are increasingly realizing that using well-being as a success measure will lead to better policies" (p. 101). O'Donnell, Deaton, Durand, Halpern, and Layard (2014)—citing Gilbert's book Stumbling on Happiness, the World Happiness Report issued in 2012 and research conducted by Diener and Suh (1999) - stated that "Overwhelming evidence confirms there is .. . real information content in" subjective well-being data (p. 30). They go on to identify three areas where subjective well-being measurements would be useful in informing policy:

[subjective well-being measurements] complement existing well-being measures at an aggregate national level; enable us to understand better the drivers of subjective well-being at the level of the individual, and to quantify the importance of different outcomes; and assist in understanding human behavior and decision making, particularly where non-market outcomes are involved, for input for other analysis, particularly cost-benefit analysis. (p. 38)

\section{The Future of Subjective Well-Being Measurements}

The interest, research, and political will to use subjective well-being measurements are steadily gathering. Today, GDP, profit, and wealth are the metrics we use at societal and individual levels to measure success. These measures, in a sense, capture and characterize our culture.

If the call for wider measures of well-being to supersede the use of GDP is answered, the measurement that is used will be part of our global culture. The next steps in this transformation have already been taken. They include the development and use of subjective well-being indicators for the ultimate goal of informing policy decisions.

\section{Developing Happiness Measurements}

The most likely place for any government or other agency to start when developing subjective wellbeing measures is the OECD Guidelines on Measuring Subjective Well-Being, issued in 2013. The OECD Guidelines had the dual purpose of "provid[ing] support for national statistics offices and other producers of subjective well-being data in designing, collecting and publishing measures of subjective well-being" (OECD, 2013b, p. 9) and "provid[ing] a resource for data producers developing their own surveys as well as a guide for ensuring that the data collected will be more internationally comparable" (p. 11). In addition to the European Unions' EU-SILC 2013 Well-Being Module Surveys (O'Donnell et al., 2014, p. 37), countries following the OECD Guidelines (OECD, 2013b) on at least one aspect of life evaluation, affect, or eudaimonic subjective well-being data collection are as follows:

- Canada: General Social Survey

- France: Survey on the Quality of Life

- Italy: Aspects of Everyday Life Annual Survey

- Mexico: National Survey of Household Expenditure

- Morocco: National Survey of Well-Being

- New Zealand: General Social Survey

- United Kingdom: Annual Population Survey, Crime Survey for England

- Wales: Wealth and Assets Survey (all U.K. surveys in line on every aspect) 
The United States' American Time Use Survey is the only survey neither in line with nor intending to be in line with, but rather informed by the OECD Guidelines (O'Donnell et al., 2014, p. 37).

\section{OECD Recommendations in Brief}

The OECD Guidelines (OECD, 2013b) cover gathering subjective well-being data in terms of life evaluation, affect, and eudaimonia (p. 9). They contain extensive suggestions on the subjects of survey design and wording, question order, recompense for responding to questions, scales, context, interview modes, translations, variables, and analysis (OECD, 2013b). Three of the many recommendations the guidelines contains are (a) using life evaluation questions, such as satisfaction with life, as these appear to be are more reliable than affect or eudaimonia questions and can yield the potentially most useful data today; (b) placing life satisfaction, affect, and eudaimonia questions first in any survey so as to remove the potential impact of asking other questions; and (c) using anchored scales.

\section{Comparing and Contrasting International Efforts to Gather Subject ive Well-Being Data for Policy}

The OECD Better Life Index (OECD, 2013a), Eurostat (n.d.a.) data, Eurofound's (2012) Quality of Life Survey, European Social Survey (n.d.a.), World Values Survey (2012), Gallup World Poll (Gallup, 2014b), Gallup-Healthways Well-Being Index (Gallup, 2011), and Happy Planet Index (The New Economics Foundation, 2012) are informing countries gathering of subjective well-being data at various degrees (see Appendix A for a description of international subjective well-being indicator efforts). The subjective well-being data these instruments gather varies greatly in spite of the $O E C D$ Guidelines on Measuring Subjective Well-Being (OECD, 2013b; see Appendix B for a comparison of subjective indicator subjective areas covered).

The only area for which all instruments collect data is their subjective well-being measuring affect, satisfaction with life, and eudaimonia. Even here, the alignment is not close. Two of the 10 instruments measure eudaimonia, six measure affect, and one instrument does not include satisfaction with life measures. Satisfaction with life is measured using the Cantril Ladder by only five of the instruments.

Within the domains of happiness, there is even less alignment. In Appendix A, the domains are grouped into 10 areas: economy/standard of living, work, governance, environment, health, community, social support, education, culture, and time balance. All instruments except the Happy Planet Index (The New Economics Foundation, 2012) include some measure of economic well-being, but the areas covered within the economic domain vary from personal living standards to national economic issues. In the other domains, the degree of differences in terms of areas covered and metrics used is to an equal or greater degree than the differences in metrics used to measure subjective well-being.

An explanation for the lack of alignment among these eight instruments informing countries and other agencies is that the subjective well-being indicators field is still in its nascence. The $O E C D$ Guidelines for Measuring Subjective Well-Being (OECD, 2013b), leave the question of "whether it is possible or desirable to move towards a greater degree of international standardization" (p. 14). Another reason may be the lack of clarity about the linkages or causality of eudaimonia on affect and satisfaction with life, satisfaction with life on affect or eudaimonia, affect on eudaimonia or satisfaction with life, and the impact of satisfaction with domains on these three aspects of experienced well-being. The issue is complex. The complexity combined with the lack of alignment among the instruments frustrates progress towards arriving at common metrics for subjective wellbeing and the domains among these instruments. 


\section{Conclusion}

While the call for the use of wider measures of well-being by governments has been heard to some extent, it has yet to be answered. Governmental agencies are in the awkward position of needing a better understanding of how to use subjective well-being measures in order to confidently replace purely economic measures. The development of subjective indicators of well-being would be aided by three activities: research into the interconnections between aspects of satisfaction with life, affect, and eudaimonia by economists; the gathering of subjective well-being data and experimentation into its application by international agencies and place-based communities; and an effort on behalf of international agencies and national governments to explore harmonization. The transition from purely economic metrics to wider measures of well-being could bring about the evolution of economics from a social science narrowly focused on production of goods and services to the good and service of society and result in a future in which sustainability, social justice, thriving economies, and individual happiness are harmonious and realistic goals.

\section{References}

Diener, E., \& Biswas-Diener, R. (2008). Happiness: Unlocking the mysteries of psychological wealth. Malden, MA: Blackwell Publishing.

Diener, E., Lucas, R., Schimmack, L., \& Helliwell, J. (2009). Well-being for public policy. Oxford, UK: Oxford University Press.

Diener, E., Wirtz, D., Tov, W., Kim-Prieto, C., Choi. D., Oishi, S., \& Biswas-Diener, R. (2009). New measures of well-being: Flourishing and positive and negative feelings. Social Indicators Research, 39, 247-266.

Eurofound. (2012). Third European Quality of Life Survey - Quality of life in Europe: Impacts of the crisis. Luxembourg, Luxembourg: Publications Office of the European Union. Retrieved from http://www.eurofound. europa.eu/pubdocs/2012/64/en/1/EF1264EN.pdf

European Social Survey. (2012). ESS Round 6 Source Questionnaire. London, UK: Centre for Comparative Social Surveys, City University London.

European Social Survey. (n.d.a.). About the Europeans Social Survey European Research Infrastructure: ESS ERIC. Retrieved from http://www.europeansocialsurvey.org/about/in dex.html

European Social Survey. (n.d.b.). ESS themes. Retrieved from http://www.europeansocialsurvey.org/data/module-index.html

European Social Survey. (n.d.c.). Rotating modules. Retrieved from http://www.europeansocialsurvey.org/methodology/questionnaire/rotating questionnaire.html

European Social Survey. (n.d.d.) Sampling. Retrieved from http://www.europeansocialsurvey.org/methodology/sampling.html

European Union. (2013). Commission implementing decision of 22 November 2013 on setting up the European Social Survey as a European Research Infrastructure Consortium (ESS ERIC). Office Journal of the European Union. Retrieved from http://www.europeansocialsurvey. org/docs/about/ERIC-ESS-OJ-30-November-2013.pdf

Eurostat. (n.d.a.) Feasibility study for well-being indicators Task 4: Critical review. Retrieved from http://ec.europa.eu/eurostat/documents/118025/118135/F easibility study WellBeing_Indicators.pdf/2475816b-9e4f-44e4-9ebf-2cd05762df77 
Eurostat. (n.d.b.) National questionnaires. Retrieved from http://ec.europa.eu/eurostat/web/incomeand-living-conditions/quality/questionn aires

Eurostat. (n.d.c.). Overview. Retrieved from http://ec.europa.eu/eurostat/web/gdp-and$\underline{\text { beyond/quality-of-life/context }}$

Eurostat. (n.d.d.). Primary variables. Retrieved from http://ec.europa.eu/eurostat/web/income-andliving-conditions/methodology/list-variables

Eurostat. (2015). Quality of life in Europe: Facts and views: Overall life satisfaction. Retrieved from http://ec.europa.eu/eurostat/statistics -explain ed/index.php/Quality of life in Europe facts and views - overall life satisfaction

Fordyce, M. (1988). A review of research on the happiness measures: A sixty second index of happiness and mental health. Social Indicators Research, 20, 355-

381. http://dx.doi.org/10.1007/BF00302333

Gallup. (2008). World poll questions. Retrieved from http://media.gallup.com/dataviz/www/WP Questions WHITE.pdf

Gallup. (2011). Gallup Healthways Well-Being Index questions. Retrieved from http://www.gallup.com/poll/146822/gallup-health ways-in dex-questions.aspx

Gallup. (2014a). Country data set details. Retrieved from http://www.gallup.com/services/177797/country-data-set-details.aspx

Gallup. (2014b). How does the Gallup World Poll work? Retrieved from http://www.gallup.com/178667/gallup-world-poll-work.aspx

Gallup. (n.d.a.). How does the U.S. Gallup-Healthways Well-Being Index work? Retrieved from http://www.gallup.com/poll/128186/gallup-health ways-in dex-work.aspx

Gallup. (n.d.b.). U.S. community well-being tracking. Retrieved from http://www.gallup.com/poll/145913/city-well-being-tracking.as px

Gilbert, D. T. (2007). Stumbling on happiness. New York, NY: Vintage Books.

Global Footprint Network. (n.d.). Data and results. Retrieved from http://www.footprintnetwork. org/en/index.php/GFN/page/footprint data and results/

Happiness Alliance. (2014, September 20) A values-based psychological theory of change for alternative measures of progress by Tim Kasser. Talks from Happiness Initiative Leadership Trainings. [Recorded lecture]. Retrieved from http://www.youtube.com/watch?v=lXEJCdceVFw

Helliwell, J., Layard, R., \& Sachs, J. (Eds.). (2012). World happiness report. Columbia University Earth Institute. Retrieved from http://www.earth.columbia.edu/sitefiles/file/Sachs\%20Writing/2012/World\%20Happiness $\% 20$ $\underline{\text { Report.pdf }}$

Helliwell, J., Layard, R., \& Sachs, J. (Eds.). (2013). World happiness report 2013. United Nations Sustainable Development Solutions Network. Retrieved from http://unsdsn.org/wpcontent/uploads/2014/02/WorldHappiness Report2013 online.pdf

Helliwell, J., Layard, R., \& Sachs, J. (Eds.). (2015). World happiness report 2015. New York, NY: Sustainable Development Solutions Network. Retrieved from http://worldhappiness.report/wp-content/uploads/sites/2/2015/04/WHR15-Apr 29-update.pdf 
Huppert, F. A., \& So, T. T. C. (2013). Flourishing across Europe: Application of a new conceptual framework for defining well-being. Social Indicators Research, 110, 837-861. http://dx.doi.org/10.1007/s11205-011-9966-7

INEGInforma. (2014, September 11). Keynote conference John Helliwell, University of British Columbia (English audio) Retrieved from https://www.youtube.com/watch?v=mdWjzxzEGU 8\&list=UUvFp7Fse31ECLPYA4g9xD9A

Kasser, T. (2002). The high price of materialism. Cambridge, MA: The MIT Press.

Kasser, T., \& Ryan, R. M. (1993). A dark side of the American dream: Correlates of financial success as a central life aspiration. Journal of Personality and Social Psychology 65, 410-422. http://dx.doi.org/10.1037/0022-3514.65.2.410

National Research Council. (2013). Subjective well-being: Measuring happiness, suffering, and Other dimensions of experience. Panel on Measuring Subjective Well-Being in a Policy-Relevant Framework. In A. A. Stone \& C. Mackie (Eds.), Committee on National Statistics, Division of Behavioral and Social Sciences and Education. Washington, DC: The National Academies Press.

O'Donnell, G. (Chair), Deaton, A., Durand, A., Halpern, D., \& Layard, R. (2014) Well-being and policy. London, UK: Legantum Institute. Retrieved from http://li.com/docs/defaultsource/com mission-on-w ell being-an d-policy/commission-on-wellbeing-and-policy-report--march-2014-pdf.pdf

Organisation for Economic Cooperation and Development (OECD). (2011). How's life?: Measuring well-being. Paris, France: OECD Publishing. http://dx.doi.org/10.1787/9789264121164-en

Organisation for Economic Cooperation and Development (OECD). (2013a). Better Life Index 2013: Definitions and metadata. Retrieved from http://www.oecd.org/statistics/OECD-Better-LifeIndex-2013-definitions.pdf

Organisation for Economic Cooperation and Development (OECD). (2013b). OECD guidelines on measuring subjective well-being. Paris, France: OECD Publishing. Retrieved from http://dx.doi.org/10.1787/9789264191655-en

Organisation for Economic Cooperation and Development (OECD) Stat. (2013). Better Life Index: Edition 2013. Retrieved from http://stats.oecd.org/Index.aspx?DataSetCode=BLI

Office of National Statistics. (2015, March 27). Personal well-being three year dataset maps (interactive and static). Retrieved from http://www.ons.gov.uk/ons/rel/wellbeing/m easuringnational-well-being/pers on al-well-being-in-the-uk--three-year-data-2011-2014/rpt-pers on alwell-being-2.html

Pickett, K., \& Wilkinson, R. (2009). Spirit level. New York, NY: Bloomsbury Press.

State of global well-being: Results of the Gallup-Healthways Global Well-Being Index. (2014). Retrieved from http://info.healthways.com/hs-fs/hub/162029/file-1634508606pdf/WBI2013/Gallup-Healthways State of Global Well-Being vFINAL.pdf

Stiglitz, J., Sen, A., \& Fitoussi. J.P. (2009, September). Report by the Commission on the Measurement of Economic Performance and Social Progress. Retrieved from http://www.stiglitz-sen-fitou ssi.fr/docum ents/rapport anglais.pdf

The New Economics Foundation. (2012). Happy Planet Index: 2012 Report: A global index of sustainable well-being. Retrieved from http://www.happyplanetin dex.org/assets/happyplanet-index-report.pdf 
The New Economics Foundation. (n.d.). Happy Planet Index: The data. Retrieved from http://www.happyplanetindex.org/data/

United Nations Development Programme. (n.d.). Human development reports. Retrieved from http://hdr.undp.org/en

Whitby, A., Seaford, C., Berry, C., \& BRAINPOoL Consortium Partners. (2014, March 31). BRAINPOoL Project final report: Beyond GDP: From measurement to politics and policy. BRAINPOoL Deliverable 5.2, A collaborative programme funded by the European Union's Seventh Programme for research, technological development and demonstration under Grant Agreement No. 283024. World Future Council. Retrieved from http://www.brainpoolpr oject. eu/wp-content/u ploads/2014/05/BRAINPOoL-Project-FinalReport.pdf

World Values Survey Association. (2010-2012). World Values Survey Wave 6 2010-2014 (Official Aggregate v.20150418). Madrid, Spain: Asep/JDS. Retrieved from http://www.worldvaluessurvey.org/WVSDocum entationW V6.jsp

World Values Survey. (n.d.a.). Findings and insights. Retrieved March 29, 2015 from http://www.worldvaluessurvey.org/WVSContents.jsp

World Values Survey. (n.d.b.). Fieldwork and sampling. Retrieved from http://www.worldvaluessurvey.org/WVSContents.jsp?CMSID=FieldworkSam pling

World Values Survey. (n.d.c.). Who we are. Retrieved from http://www.worldvaluessurvey.org/WVSContents.jsp?CMSID=WhoWeAre

Zencey, E. (2013, March 26). Sustainable, happy, efficient: A complete indicator of well-being. Policy Innovations. Retrieved from http://www.policyinnovations.org/ideas/innovations/data/000238 


\section{Appendix A}

\section{International Subjective Well-Being Indicator Efforts}

\section{OECD Better Life Index}

The OECD Better Life Index is an online interactive tool produced by the Organisation for Economic Cooperation and Development (OECD, 2013a). The OEDC Better Life Index includes subjective and objective indicators (noted in parenthesis) for the following areas:

- Jobs (earning, job security, unemployment-objective),

- Income (household income and wealth-objective),

- Housing (conditions and spending, percent of income, basic facilities, rooms per personsubjective and objective),

- Civic engagement (voter turnout, trust in government-subjective and objective),

- Environment (air pollution and water quality-objective),

- Health (self-reported health and life expectancy-subjective and objective),

- Community (quality of support from friends and family-subjective),

- Safety (homicide rate and self-reported assault rate-subjective and objective),

- Education (educational levels, skills, performance levels-objective),

- Work-life balance (time devoted to leisure, working long hours paid and unpaid-subjective) and

- $\quad$ Subjective well-being (OECD Stat, 2013).

Subjective well-being is measured using the Cantril Ladder. The OECD's (2011) "How's Life? Measuring Well-Being" contemplates affect but the OECD Better Life Index (2013a) does not include data on affect. The OECD Better Life Index draws data from many different data sources including various European Union agencies, World Bank National Statistics Offices, Gallup World Poll, as well as its own databases.

\section{Eurostat}

Eurostat is the European Union's office of statistics. Its GDP and Beyond program focuses on filling the "statistical gap" (Eurostat, n.d.d.) between the GDP and the governments need for wider measures of societal and environmental well-being with multidimensional (rather than composite) indicators and data.

Eurostat issued the "Feasibility Study for Well-Being Indicators" with the intent "to pave the pathway towards a robust and complete indicator (set) of European well-being" (Eurostat, n.d.a, p. 4). It states,

The final objective for WB-measurement and -analysis is to provide policy makers information about what makes European citizens (un)happy; and in particular: what are the most important differences between the existing diversity of subgroups of society, when talking about "overall well-being" (in order to set up a [set of] targeted WB-policy[-ies])? (p. 44, sec. 6.3)

The World Happiness Report (2014) sites the Eurostat's Statistics on Income and Living Conditions (EU-SILC) as the source for well-being data for many European countries (p. 4). It includes indicators for the areas of

- Employment/labour

- Income/material deprivation 
- Housing and households

- Education

- Health (Eurostat, n.d.c.).

Some of the EU-SILC surveys include questions on satisfaction with life, eudaimonia, and affect (Eurostat, n.d.b.). The EU-SILC data are available online for download without cost.

\section{Eurofound's Quality of Life Survey}

In 2012, Eurofound issued the Third Quality of Life Survey based on objective and subjective indicators and has included life satisfaction questions since 2003 with the goal of providing relevant data to guide European institutions (pp. 9, 11). The report provides one of the clearest and potentially useful (to governments and other agencies) examples of how subjective well-being data can be portrayed. It includes indicators for the following areas:

- Employment and work-life balance (employment and unemployment, weekly working hours, unpaid work-care and housework, work-time arrangements, work-life balance),

- Living standards and deprivation (ability to make ends meet, household debts, standards of living and material deprivation, income insecurity),

- Home, housing, and local environment (local neighborhood, home, and housing),

- Quality of society (trust in people, trust in public institutions, perceived social tensions),

- Public services, health and health care (health and health care, perceived quality of public services, access to public services),

- Social exclusion and community involvement (perceived social exclusion, community involvement),

- Family and social life (household size and composition, contact with family members and friends, sources of support, satisfaction with family life and social life) and

- Subjective well-being (Eurofound, 2012).

For Eurofound's Quality of Life Survey (2012), subjective well-being includes overall life satisfaction, satisfaction with areas including health, family and standard of living as well as positive and negative affect, or "happiness" (p. 16).

\section{European Social Survey}

The European Union's European Research Infrastructure Consortium controls the European Social Survey (European Union, 2013). There are five goals for the European Social Survey (n.d.a): bolstering standards for questionnaire design, sampling and data collection, introducing indicators of nation progress, training social researchers, and improving the visibility of data for policy makers and the public. Data is provided online and downloadable for no cost. There are core modules and rotating modules. Core modules are used on a periodic basis continually. Rotating modules may be used for discrete time periods. The core modules are

- Media and social trust (trust in people, media and internet use),

- Politics (trust in institutions, voting, party affiliation. satisfaction with government),

- Gender, household (number and gender of people living in household)

- Sociodemographics (household, marital status, education, employment, satisfaction with job and time-balance),

- Human values (importance of creativity, fun, understanding, traditions, environment, financial status, success, security, etc.), and

- Subjective well-being (affect, social support, sense of safety, subjective health, discrimination; European Social Services, n.d.c.). 
Other areas covered between 2002 and 2012 include economic morality, family work and well-being, citizen involvement, democracy, justice, welfare attitudes, immigration, health and care, ageism, timing of life, personal and societal well-being (European Social Survey, n.d.b.).

The Round 6 Personal and Societal Well-Being module is a set questions in the Round 6 Source Questionnaire that focuses on satisfaction with life, affect, and eudaimonia, with questions for the areas of resilience, meaning and purpose, autonomy and control, engagement, competence, vitality, involvement in well-being promoting activities, optimism, self-esteem, thick relationships, thin social relationships, active involvement, subjective socioeconomic position, satisfaction with job, satisfaction with work/life balance, social optimism, emotions, and overall satisfaction (European Social Survey, n.d.b.). The satisfaction with life questions used are, "All things considered, how satisfied are you with your life nowadays?" "Taking all things together, how happy would you say you are?" and other questions on positive and negative affect (depressed, restless lonely, sad, anxious, calm and peaceful, etc.; European Social Survey, 2012, pp. 23-26). The data for this questionnaire as well as all others is provided free online. Data is collected through random sampling methods, with face-to-face interviews or, in some cases, self-administration, of between 1,500 and 1,800 people in a country in Europe in 2-year intervals starting in 2002 (European Social Survey, n.d.d.).

\section{World Values Survey}

The World Values Survey (n.d.c.) is a global not-for-profit with the goals of providing data "to help scientists and policy makers understand changes in the beliefs, values and motivations of people throughout the world"(p.3). All data is available online for download for no cost. The World Values Survey (n.d.a.) organizes its data in terms of values in two categories: traditional or secular rational values and survival or self-expression values.

Areas covered in the traditional or secular rational values are

- Authority (autonomy/freedom of choice, nationalism, trust in institutions),

- Religion (participation in religion, role of religion),

- Family (family values, respect for youth, middle aged and elders,) and

- Gender equality (job and education equality).

Areas covered in the survival or self-expression values are:

- Economy (personal finances, deprivation, income equality, class, work, job security),

- Globalization (human rights, role of science and technology, communications use),

- Democratic engagement (democratic participation, role of government, trust in elections),

- Social security (discrimination, volunteering, trust, care for others, safely, crime, national security),

- Environmental protection (environmental prioritization, activism), and

- Tolerance (discrimination, use of violence, ethical behavior; World Values Survey, 2012, n.d.a.).

The 2010-2012 World Values Survey includes questions for satisfaction with life and affect: "All things considered, how satisfied are you with your life as a whole these days?" and "Taken all things together, would you say you are ... very happy, rather happy, not very happy, not at all happy?" (World Values Survey, 2010-2012, pp. 2-3). Random sample surveys has been conducted since 1981 in 100 countries, with at least 1,000 people per country (World Values Survey, n.d.b.). 


\section{Gallup World Poll}

Gallup, Inc., is an employee-owned privately held management consulting company. The Gallup World Poll is one of its products. Gallup World Poll is a questionnaire is composed of into core and region-specific questions. The core questions focus on the following circumstances or domains:

- Business and economics (business, personal and country economics),

- Food and shelter (affordability, deprivation),

- Citizen engagement (social support, democratic participation, volunteerism, donations, immigration),

- Government and politics (leadership performance, national government elections),

- Corruption (government and business),

- Environment and energy (climate change, conservation of natural resources, environmental conservation and protection, quality of air and water, public transportation and infrastructure),

- Personal health (perception of health, occurrence of pain, negative affect),

- Community basics (satisfaction with education, environment, healthcare, housing, infrastructure),

- Education and families (child welfare, education, respect for youth),

- Social issues (diversity, race, ethnicity, culture, poverty),

- Law and order (personal security, crime, confidence in governmental institutions),

- Religion and ethics (religion, acceptance of use of violence),

- Work (employment, work quality), and

- Well-being (satisfaction with life, affect; Gallup, 2008).

The Gallup World Poll (2008) includes questions within the domains specifically crafted for a country, such as, for Asia, the question, "How many children in this country are required to work long hours to assist in providing for their families?" (p. 8), and for former soviet countries, "What kind of meat/sausages do you eat?" and "In your opinion, which political system is the most suitable for this country: the Soviet system, a strong authoritarian system, a monarchy, a Western-style democratic republic, or an Islamic republic?” (pp. 10-11).

The Gallup World Poll data is one of the data sources for the World Happiness Report and the OECD (2013a) Better Life Index. Gallup also publishes articles about its findings and provides a description of the data set online (Gallup, 2014a). For the Gallup World Poll, Gallup conducts about 1,000 face-to-face or telephonic interviews in 160 countries, often on an annual basis (Gallup, 2014b). The Gallup World Poll data is available for a fee.

\section{Gallup-Healthways Well-Being Index}

The Gallup-Healthways Well-Being Index is different from the Gallup World Poll in that it has a narrower scope, focusing on aspects of well-being, includes data for cities and state in the United States as well as countries internationally (Gallup, 2011.). Gallup partners with Healthways, a publicly traded company to issue the index. The index includes questions in the areas of

- Financial (personal financial stress and security, standard of living, deprivation, shelter, job satisfaction, productivity, work environment),

- Physical (health conditions, access to health care, exercise, eating, smoking, drinking),

- Community (safety, pride, livability, access to water),

- Social (relationship, family and friends), and

- Purpose (motivation and achievement, recognition, liking daily activities; Gallup-Healthways Well-Being Index, 2014). 
The index was updated in 2014, and includes questions covering satisfaction with life (Cantril Ladder and affect). The areas covered in the prior Gallup-Healthways Well-Being Index, used between 2008 and 2011, were

- Basic access (shelter, deprivation, access to medical care, safety, livability),

- Physical health (health, health conditions),

- Healthy behavior (smoking, eating, exercising),

- Work (job satisfaction, treatment),

- Emotional health (affect, energy), and

- Satisfaction with life (Cantril Ladder; Gallup, 2011).

The data for the United States is collected more frequency than that for countries (Gallup, n.d.a.). Country level data is collected following a similar methodology to the Gallup World Poll (GallupHealthways Well-Being Index, 2014, p. 112). The data for the United States is available online (Gallup, n.d.b.). Data for areas not listed are available for a fee.

\section{Happy Planet Index}

The Happy Planet Index is a composite measurement issued by a British nonprofit New Economics Foundation in 2006, 2009, and 2012. The Happy Planet Index (The New Economics Foundation, n.d.) is different from other happiness or subjective well-being indicators in that it provides a single number and rates countries in comparison to each other. The Happy Planet Index (2012) is arrived at by multiplying the Cantril Ladder score for a country gathered by the Gallup World Poll, with the life expectancy score gathered by the United Nations Development Programme's (n.d.) Human Development Report, and dividing the product by the ecological footprint for countries issued by the Global Footprint Networks National Footprint accounts (The New Economics Foundation, p. 19). The Happy Planet Index reports are available online for free. 


\section{Appendix B}

\section{Subjective Well-Being Indicators Subject Areas Used by Institutions Informing the Happiness and Well-}

Being/Beyond GDP Movement

\begin{tabular}{|c|c|c|c|c|c|c|c|c|}
\hline $\begin{array}{l}\text { Subject } \\
\text { Areas }\end{array}$ & $\begin{array}{l}\text { OECD Better } \\
\text { Life Index }\end{array}$ & $\begin{array}{c}\text { Eurostat } \\
\text { (EU-SILC) }\end{array}$ & $\begin{array}{l}\text { Eurofound's } \\
\text { Quality of Life } \\
\text { Survey }\end{array}$ & $\begin{array}{c}\text { European Social } \\
\text { Survey }\end{array}$ & $\begin{array}{l}\text { World Values } \\
\text { Survey }\end{array}$ & Gallup World Poll & $\begin{array}{c}\text { Gallup-Healthways } \\
\text { Poll }\end{array}$ & $\begin{array}{l}\text { Happy Planet } \\
\text { Index }\end{array}$ \\
\hline \multirow{3}{*}{ 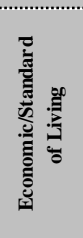 } & & $\begin{array}{l}\text { Material living } \\
\text { conditions }\end{array}$ & Living standards & & & $\begin{array}{l}\text { Personal economics and } \\
\text { Food and shelter }\end{array}$ & Financial & \\
\hline & Housing & Housing & $\begin{array}{l}\text { Home, housing, and } \\
\text { local environment }\end{array}$ & $\begin{array}{l}\text { Gender and } \\
\text { household }\end{array}$ & & & & \\
\hline & & $\begin{array}{l}\text { Economic and } \\
\text { physical safety }\end{array}$ & & & Economy & Business and economics & & \\
\hline 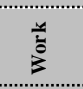 & & $\begin{array}{l}\text { Productive or main } \\
\text { activity }\end{array}$ & Employment & & & Work & Job and work & \\
\hline 这. & Civic engagement & $\begin{array}{l}\text { Governance and } \\
\text { basic rights }\end{array}$ & & Politics & $\begin{array}{l}\text { Democratic } \\
\text { engagement }\end{array}$ & Citizen engagement & & \\
\hline 离 & & $\begin{array}{c}\text { Natural and living } \\
\text { environment }\end{array}$ & & & $\begin{array}{c}\text { Environmental } \\
\text { protection }\end{array}$ & Environment and energy & & \\
\hline 咅 & Health & Health & $\begin{array}{l}\text { Health and health } \\
\text { care }\end{array}$ & Health & & Personal health & Physical (health) & \\
\hline \multirow[t]{2}{*}{ : } & Community & & $\begin{array}{c}\text { Social exclusion and } \\
\text { community } \\
\text { involvement }\end{array}$ & Human values & & Community basics & Community & \\
\hline & Safely & Trust in others & Quality of society & $\begin{array}{l}\text { Media and social } \\
\text { trust }\end{array}$ & Social security & Law and order & & \\
\hline 這 & & Social interactions & Family and social life & Social support & Family & & Social & \\
\hline 言 & & Education & & & & Education and families & & \\
\hline \multirow{2}{*}{ 竞 } & & & & & Religion & Religion and Ethics & & \\
\hline & & Discrimination & & Discrimination & Gender equality & Social issues & & \\
\hline 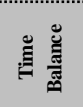 & $\begin{array}{l}\text { Work-life } \\
\text { balance }\end{array}$ & Leisure & Work-life balance & & & & & \\
\hline$\sum_{\omega}^{\infty}$ & Cantril Ladder & $\begin{array}{l}\text { Cantril Ladder, } \\
\text { affect, and } \\
\text { eudaimonia (for } \\
\text { some countries) }\end{array}$ & $\begin{array}{l}\text { Satisfaction with life } \\
\text { and affect }\end{array}$ & $\begin{array}{l}\text { Satisfaction with } \\
\text { life and affect }\end{array}$ & $\begin{array}{l}\text { Satisfaction with } \\
\text { life and affect }\end{array}$ & Cantril Ladder, affect & $\begin{array}{l}\text { Cantril Ladder, } \\
\text { affect, and } \\
\text { eudemonia }\end{array}$ & Cantril Ladder \\
\hline
\end{tabular}


The Journal of SocialChange, sponsored by Walden University, welcomes manuscripts focusing on interdisciplinary research in social change that improves the human condition and moves people, groups, organizations, cultures, and society toward a more positive future.

Walden University Publishing: http://www.publishing.waldenu.edu 